\title{
A Systems-Approach Model of Mental Toughness: Understanding Inputs, Processes and Outputs
}

\author{
Sarah Sorensen, Grant Schofield, Aaron Jarden \\ Human Potential Centre, Auckland University of Technology, Auckland, New Zealand \\ Email: aaron.jarden@aut.ac.nz
}

How to cite this paper: Sorensen, S., Schofield, G., \& Jarden, A. (2016). A SystemsApproach Model of Mental Toughness: Understanding Inputs, Processes and Outputs. Psychology, 7, 1402-1423.

http://dx.doi.org/10.4236/psych.2016.712141

Received: August 31, 2016

Accepted: October 31, 2016

Published: November 3, 2016

Copyright $\odot 2016$ by authors and Scientific Research Publishing Inc. This work is licensed under the Creative Commons Attribution-NonCommercial International License (CC BY-NC).

http://creativecommons.org/licenses/by-nc/

$\underline{4.0 /}$

\section{Open Access}

\begin{abstract}
Despite its rising prominence in the academic literature, the underlying inputs, processes and outputs of mental toughness remain relatively unexplored (Hardy, Bell, \& Beattie, 2014). As such, the purpose of the study is to present a systems-approach model of mental toughness that classifies attributes of mental toughness within the aggregated system of inputs, processes and outputs. To this end, lay participants $(n=138)$ were requested to provide a list of attributes of mental toughness in the form of a written questionnaire. Following guidelines for conducing Deductive Thematic Analysis (DTA) by Braun and Clarke (2006), and on the basis of similar frameworks by Hagerty et al. (2001) and Jayawickreme, Seligman and Foregard (2012), data were thematically analyzed and organized into inputs, processes and outputs. The resultant systems-approach model included a number of inputs (personal resources, stressors), processes (strength, accommodation) and outputs (surviving, striving, thriving) of mental toughness. Based on these findings, mental toughness was subsequently defined as a resistance to psychological disintegration under stress. As this model advances current theoretical knowledge, implications for future conceptualization, measurement and development of mental toughness are discussed.
\end{abstract}

\section{Keywords}

Mental Toughness, Stress, Positive Psychology, Systems-Approach Model, Definition

\section{Introduction}

Mental toughness has received increased scholarly attention over the past decade due to its propensity to facilitate thriving (Gucciardi, Hanton, Gordon, Mallett, \& Temby, 2015; Jones \& Moorhouse, 2007; Weinberg et al., 2011) within a range of stressful sporting, academic, business and military contexts (Gucciardi, Hanton, Gordon, Mal- 
lett, \& Temby, 2015). In an attempt to understand and replicate this psychological asset, researchers have produced a myriad of multidimensional conceptualisations that identify the attributes, causes, underlying processes and/or outputs of mental toughness (e.g., Clough \& Strycharczyk, 2012; Coulter, Mallet, \& Gucciardi, 2010; Gucciardi, Gordon, \& Dimmock, 2009a; Jones, Hanton, \& Connaughton, 2002). Despite their contribution to understanding mental toughness, however, no single conceptualisation comprehensively encompasses the entire system of causes, processes and outputs involved in mental toughness (Hardy et al., 2014). Considering that these elements collectively carry important implications for mental toughness theory, measurement and interventions, we aim to inclusively conceptualise the causes, processes and outputs within a systems-approach model of mental toughness.

Previously, researchers investigated the attributes of mental toughness to provide a comprehensive description of mental toughness (Middleton, Marsh, Martin, Richards, \& Perry, 2004) and inform a number of valuable measurement tools (e.g., Clough, Earle, \& Sewell, 2002). For example, Jones et al. (2002) and Thelwell, Weston and Greenlees (2005) identified twelve attributes of mental toughness, with an emphasis on determination, focus, confidence and control as defining attributes. Based on the related personality construct of hardiness, Clough et al. (2002) instead suggested attributes of challenge, commitment, confidence and control and subsequently developed the Mental Toughness Questionnaire 48 (MTQ48). Middleton, Marsh, Martin, Richards and Perry (2004) followed these accounts with a multidimensional description of mental toughness attributes, which corroborated as well as extended those attributes identified in previous literature.

Despite their contribution to mental toughness knowledge, however, researchers recognised a need for a deeper understanding of the inputs, processes and outputs underlying these attributes of mental toughness (Gucciardi et al., 2009a), and as such, produced a number of models that accounted for these fundamental systematic elements. For example, Bull, Shambrook, James and Brooks (2005) identified inputs and processes involved in mental toughness by distinguishing environmental and personality inputs from attitudinal and cognitive manifestations of mental toughness. Although not explicitly, Gucciardi, Gordon and Dimmock (2008) and Coulter, Mallett and Gucciardi (2010) account for processes and outputs in their models by classifying attributes into characteristics, cognitions, behaviours and situations of mental toughness (Gucciardi et al., 2009a). These findings were further extended by Gucciardi et al. (2009a), who identified positive iterative appraisals as the process underlying the translation from mental toughness attributes into mentally tough outcomes.

As a systems approach was not the main focus of these studies, however, differentiation among inputs, processes and outputs is piecemeal, not explicitly recognised and/or is ill-defined. For example, Bull et al. (2005) consider confidence as a personality input whereas this attribute is considered as a cognitive element by Coulter et al. (2010). As such, the underlying system of inputs, processes and outputs remains relatively unknown in the mental toughness literature. 
We thus aim to build on these existing models of mental toughness by providing a systems-approach model of mental toughness. To this end, we aim to classify attributes of mental toughness into inputs, processes and outputs according to the established frameworks developed by Hagerty et al. (2001) and Jayawickreme et al. (2012). Addressing similar conceptual issues in the wellbeing literature, Hagerty et al. (2001) and Jayawickreme et al. (2012) implemented a systems-theory approach to consolidate and organise multiple attributes of wellbeing into inputs, processes and outputs. We subsequently integrate criteria from these frameworks to distinguish inputs, processes and outputs of mental toughness (See Table 1). On the basis of these frameworks, therefore, inputs are identified as environmental/exogenous (Hagerty et al., 2001; Jayawickreme et al., 2012) and endogenous variables, such as personality traits (Jayawickreme et al., 2012). Process or throughput variables are defined as an individual's reaction and choices in these environments (Hagerty et al., 2001) and capabilities and subjective states, including beliefs or cognitions, cognitive evaluations, moods and emotional states (Jayawickreme et al., 2012). Finally, output variables are the result of inputs and processes, which are identified as voluntary behaviours (Jayawickreme et al., 2012) and final outcomes of the system (e.g., happiness, survival and contribution to humanity; Hagerty et al., 2001; see Table 1).

By presenting a systems-approach model of mental toughness, we aim to consolidate and build on existing models to advance the conceptual understanding, measurement

Table 1. Criteria used to classify themes and sub-themes from the raw data.

\begin{tabular}{|c|c|}
\hline & Input variables \\
\hline 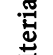 & Exogenous or environmental variables \\
\hline 莣 & Endogenous variables, e.g., personality \\
\hline
\end{tabular}

Resources Stressors (external stress and internal strain)

\section{Strength of psychological} functioning under stress

Performing and retaining the capacity to understand, reason and make accurate and timely judgements (cognitive faculty)

Performing and retaining the capacity for purposeful direction of effort towards needs and goals (conative faculty)

Performing and maintaining favourable affect (affective faculty)

Proces
Subs
he
he
ty

Process variables

Choices

Reactions

Capabilities

Subjective states

Accommodation of limitations

or barriers to psychological functions

Tolerance of uncertainty

Awareness and promotion of others' needs before one's own

Tolerance of unfulfilled needs Tolerance of uncontrollable internal, external and future environments Emotional attachment to external entities

Tolerance of uncontrollable negative affect
Preservation of wellbeing and intended behaviour under stress (surviving)

Goal maintenance (striving)

Growth and achievement (thriving) 
and development of mental toughness. To this end, we attained attributes of mental toughness through written questionnaires and thematically analysed responses following guidelines by Braun and Clarke (2006). Using the aforementioned criteria, we subsequently allocated attributes to inputs, processes and outputs to arrive at a systemsapproach model of mental toughness.

\section{Method}

Data from this study have also been reported elsewhere by Sorensen, Jarden, \& Schofield (2016), who utilise a prototype analysis to investigate differences between lay and sporting or expert perceptions of mental toughness. However, the current study is different insofar that it is concerned with uncovering the underlying mechanisms of mental toughness vis-à-vis population differences. Participants and procedures used in collection of data are described below.

\subsection{Participants}

One hundred and thirty eight laypeople participated in the current research. Due to an accidental omission of demographic questions from the original questionnaire, demographic information was collected retrospectively from participants. Fifty-one (37\%) participants responded to the demographic questionnaire. These respondents consisted of females (56\%) and males (43.1\%) who ranged in age between 18 and 64+ years, with the biggest age groups being 50-64 years old (35.3\%) and 35-49 years old (33.3\%).Most participants were European/NZ European (92\%) with remaining ethnicities being Māori (2\%), Indian (2\%) and other (4\%). Participants worked across a range of industries in entry and managerial-level positions.

\subsection{Procedure}

Participants were invited to participate in the research at various routine group meetings or online via social media in July 2015. The invitation included a request for all interested participants to attend a data collection session after the meeting (in-person) or contact the first author via email (online) if they were interested in participating. The information sheet, consent form and questionnaire were then disseminated to participants either in person, or via email (for those restricted by location).

Once participants had read the information sheet and signed the consent form, the questionnaire invited participants to take 15 minutes to freely produce all features associated with MT, according to the following instructions (adapted from Fehr \& Russell, 1984, Study 6):

This is a study on the attributes that people think of when they think of the word mental toughness in everyday situations. For example, if you were asked to list the attributes of a person experiencing fear, you might write possible danger occurs, attention is focused on the threat, heart beats wildly, the person runs as fast as they can. In the current study, we are not interested in attributes of fear but in attributes of mental toughness in everyday situations. Imagine that you are explaining the word mental 
toughness to someone who has no experience of mental toughness. Include the obvious. However, try not to just free-associate. We're interested in what is common to instances of mental toughness. Remember that these attributes can be positive or negative.

These instructions were followed by a statement to re-clarify the question and prompt participants:

What, in your opinion, are the key attributes of mental toughness? Please list as many as you can below.

Participants were provided with 15 blank lines to enter their responses, and were encouraged to take as much time as needed to generate as many attributes of mental toughness as possible. Once participants had completed and submitted the questionnaire, snowball sampling was encouraged by asking participants if they were affiliated with other community or occupational groups who may appreciate the opportunity to participate in this research. In this case, the researcher worked with the participant or an appropriate group representative to present the research in the appropriate format (in-person or online). This process was repeated until a sufficient sample size was obtained.

\subsection{Data Analysis}

Deductive Thematic Analysis (DTA; Braun \& Clarke, 2006) was used in the present research. Following recommendations by Braun and Clarke (2006), this "top-down" approach is best suited for research that is driven by a specific question (i.e., "what are the inputs, processes and outputs of mental toughness?") and guided by previously established frameworks (i.e., Hagerty et al, 2001; Jayawickreme et al., 2012). On this basis, Braun and Clarke's (2006) six-phase iterative approach was followed:

1) Data familiarisation and identification of meaningful units. Data was iteratively read and meaningful data extracted for coding.

2) Initial code generation. Units of data were assigned none, one or multiple codes. Coding was conducted according to the surface or explicit meanings of raw data, and as such, coding aligned with an essentialist/realist approach (Braun \& Clarke, 2006).

3) Identification of themes. Codes were initially allocated into the major themes of inputs, processes and outputs according to criteria set out by Hagerty et al. (2001) and Jayawickreme et al. (2012) (See Table 1 for criteria). Within inputs, processes and outputs, similar codes and their constituent data extracts were grouped together to form sub-themes.

4) Reviewing themes. Sub-themes and codes were reviewed, combined, separated and/or re-categorised into inputs, processes and outputs according to their constituent data extracts and the dataset as a whole. This process was maintained until a satisfactory level of data representation was achieved and until themes collectively provided an accurate representation of the dataset.

5) Defining themes. Upon finalisation of themes, constituent raw data was inspected to identify and describe the essence of each theme. 


\section{6) Identification of extract examples for the final report.}

Although presented in order, these phases were approached and organically revisited as the analysis progressed. The result was an exhaustive analysis of the data, with $94 \%$ of data allocated to at least one code.

\section{Results}

Participants generated an average of 9.28 codes each $(S D=5.79$, range 2-34). Analysis of these codes within the major themes of inputs, processes and outputs revealed a number of sub-themes, as presented in Table 1 (see Appendix for a full list of themes). These themes included inputs (personal resources, stressors), processes (strength, accommodation) and outputs (surviving, striving, thriving) of mental toughness.

\subsection{Theme 1: Inputs}

A number of exogenous and endogenous influences were identified by participants, which generally fell into two themes of personal resources and stressors.

\subsubsection{Personal Resources}

A collection of personality traits were the largest group of personal resources identified by participants. In particular, one participant referred to the inherent vis-à-vis developed dimension of mental toughness: "personality-it is an inane part of who you are. Some people are able to thrive under stress while others find it much more difficult". Other participants prescribed particular personality qualities to mental toughness, such as "stable personality", optimism, pessimism, hardiness, scepticism, adaptability, competitiveness and goal orientated.

Following personality traits, participants remarked on the value of previous experience and the competencies accumulated during these episodes. These experiences were particularly useful for generating wisdom "the ability to draw on experience, having learnt from your own or others mistakes-wisdom", skills "life/work experiences-in situations these are the skills that have come to the fore and gets you through" and self-efficacy "past experience proving 'you can survive this too!". Within the acquisition of skills, participants particularly mentioned that experience was pertinent for the development of technical skills, emotional intelligence, social intelligence and coping skills.

Similar to experience, social support was suggested as an external source of information for understanding how to navigate challenges, for example, "having good role models to learn from i.e. a boss who handles difficult situations with clients well". Perhaps not surprisingly, social support was also important for self-efficacy, emotional and motivational resources. In particular, one participant commented "channel the energy of those you admire when you're feeling small. Walk like you're Angelina Jolie”. Responses such as this also indicated that a) social support may only be considered an input variable when the source is admired by the individual, and b) that social support may act as an input variable even when the role model is not directly accessible inperson, i.e., behavioural observation or cognitive representation of significant others 
may be an effective substitute for verbal communication. In addition to these dimensions, past vis-à-vis present social support may be considered an input variable, for example, "nurture-having a supportive home life that sets you up for challenges".

A number of participants also mentioned morals and values (e.g., "having a clear moral code that you live by") and religion (e.g., "faith in God (higher power)"), which may again provide behavioural guidance and reassurance in uncertain or uncontrollable situations. Further, a number of participants noted wellness variables as an attribute of mental toughness, which included quality sleep, nutrition and being "physically well".

\subsubsection{Stressors}

Although stressors do not contribute to mental toughness per se, participants indicated that it may be impossible to understand attributes of mental toughness in a vacuum. For example, one participant commented that "mental toughness can thus include many things, and it is context dependent". Accordingly, participants included a number of contexts throughout their narratives, which generally consisted of external stress and/or internal strain.

External stressors ranged from negative situations, challenges or adversities to everyday mundane activities and obligations. Participants particularly mentioned social stressors (such as pressure to conform, conflict, confrontation, rejection and criticism) and difficulties in attaining goals (such as obstacles or problems, interruptions or distractions and negative outcomes such as mistakes, failure and defeat). Typical responses included "letting other people's jealousy, negative attitudes, doubt, and pessimism bounce off you rather than derail you" and "knowing that hurdles are a part of getting to the end result. If it is hard then less people finish". Some participants also mentioned time-poor and high-stake situations (e.g., emergencies and pressure) and those that are psychologically and ethically challenging (e.g., change, out-of-control situations, poor odds of success, unexpected situations, difficult decisions, unpleasant/inconvenient/ unenjoyable but necessary tasks and situations that are unethical or unfair). Attributes were further framed within specific life situations, such as social (caregiving, helping others in distress, bereavement, work/family conflicts, responsibilities), financial (financial strain), physical (military training, sport, gym, running), vocational (stressful job, studying) and psychological (witnessing/experiencing traumatic events, waiting) circumstances.

On the other hand, participants indicated that mental toughness was also necessary for dealing with internal strain. Internal strain included physical (fatigue, pain, illness and discomfort), psychological (mental fatigue, uncertainty, uncontrollability, threat to wellbeing, mental illness, poor motivation, self-doubt and other negative beliefs) and emotional (disappointment, fear, guilt, sadness and emotional fatigue) conditions. In describing these internal strains, participants mostly suggested that they were derived from external occurrences (e.g., "situations which may cause negative emotional responses in an individual"). 


\subsection{Theme 2: Processes}

Within this category, two potentially conflicting processes were identified. These subthemes were highlighted by a number of conflicting concepts that often occurred within the same sentence. For example,

"Goal oriented but adaptable to change".

"Be proud of our achievements and be proud of ourselves-Also be humble and compassionate".

"Keeps going and trying again or something different".

"Being able to stop what you are doing to rectify a 'wrong' situation directly in front of you AND not 'walking past' it. If you do walk' past it', being able to reconcile your own reaction or 'inaction"'.

A few participants further identified that the effective use of any one process depends on situational conditions, such as uncontrollability: for example,

"While I have said to be persistent, sometimes mental toughness can simply be to accept a situation, especially if it is something that can't be changed. Sometimes it can mean walking away. Sometimes it can be to be acquiescent to avoid conflict-this doesn't mean you are giving in".

"Picking your battles-acknowledging that you can't win/succeed at everything. Knowing when, and when not to use your energy to persevere with something".

"If appropriate, choose not to respond/react".

This dichotomy was labelled strength and accommodation, and is discussed in more detail below.

\subsubsection{Strength}

Responses under the theme of strength pertained to the capacity to perform and maintain various psychological functions under stress. Within this theme of strength, participants commonly referred to the power to perform and maintain cognitive (thinking, reasoning and judgement), conative (will and volition) and affective (emotive and energising states) functions under stress. Some representative quotes for this overarching theme include: "strong mentally" and "being able to draw on inner strength".

First, cognitive functions included the speed and quality of thinking, reasoning and judging under stress particularly in the process of problem-solving and decision-making (e.g., "thinking 'on your feet", "being able to think rationally under pressure"). The ability to perceive, know and understand was also reflected in narratives, which included awareness and comprehension of internal variables (e.g., internal states and the self; "having a realistic understanding of your own strengths and weaknesses"), external situations (e.g., "having an awareness of your situation and possible consequences"), other people (e.g., "the ability to recognise a strong ally") and the past (e.g., "reflecting on past experiences"). As well as performance of these functions, participants also commented that mental toughness involved the maintenance of cognitive capacities, such as maintaining the ability to think (e.g., "maintain the capacity to think clearly in demanding situations") and remaining rational, logical and objective (e.g., "staying sane", "keep the head logical" and "retains objectivity"). 
Second, conative attributes of mental toughness included the power to perform and maintain purposeful striving towards goals and needs. As a starting point, individuals require awareness of their needs and "possible selves" (Huitt \& Cain, 2005). This was reflected in participant's narratives, such that participants felt that sometimes it was necessary to be selfish and prioritise their needs above others' needs: "sense of selflooking after yourself and making sure you make your needs and wants a priority". Similarly, awareness of "possible selves" included the presence and clarity of goals, purpose, vision and ambitions and an ability to "visualise the outcome/results of what you're doing". Further, belief in one's ability to achieve these "possible selves" was commonly noted as an attribute (e.g., "belief in yourself/confidence in your ability"). In order to actualise these "possible selves", mental toughness was also associated with the conative functions of directed attention (i.e., focus and concentration), prioritisation, planning and preparation. Coinciding with the exercise of one's will, participants also frequently mentioned mental toughness as the freedom to choose and/or control emotions (e.g., detachment from outcomes and situations, emotional control), thoughts (e.g., directed forgetting, thought blocking, cognitive distancing), actions (e.g., self-discipline, self-control, self-motivating) and external environments (e.g., being proactive, avoiding distractions). Similar to the cognitive component, participants emphasised not only the power to perform these functions, but also the ability to maintain conative functions under stress. Maintenance of conation included maintaining focus, control and self-belief (e.g., "maintain focus under pressure, to make sure the job gets done", "being able to maintain control over the way that you react and respond to stressful and challenging situations" and "in the face of adversity continuing on with belief in your path and direction you are taking").

Finally, participants identified favourable affective states as hallmarks of mental toughness. Four affective dimensions were identified as typical to mentally tough individuals: the presence of positive emotions, absence of strong emotion, absence of negative emotions, and energising states. Specifically, participants commented on positive moods (e.g., "buoyant"), calmness (e.g., "the ability to crisis manage without panic and disorder") as well as the absence of fear (e.g., "fearlessness"). Participants also referenced the presence of energising states which included the feeling of motivation and its subsidiaries (such as desire, commitment and obsession). Again, as with cognition and conation, the maintenance of these states under stress (rather than just their presence) was commonly noted as an important attribute of mental toughness (e.g., "stay calm, no matter what", "the ability to remain positive in adversity").

\subsubsection{Accommodation}

Although mental toughness was associated with the capacity to perform and maintain cognitive, conative and affective functions, participants simultaneously recognised that mental toughness abided in the ability to accommodate intrinsic weaknesses or barriers (i.e., internal strains) within cognitive, conative and affective faculties.

Within cognitive operations, an ability to tolerate limitations in one's ability to know, understand and judge situations (such as uncertainty or imperfect knowledge), was 
commonly cited as an attribute. Participants included being comfortable with uncertainty: "being able to cope with ambiguities, paradoxes and uncertainties that life inevitably throws up. Not needing things to be either black or white or put in boxes", an open-minded approach to uncertain situations and outcomes: "the willingness to give something a go that is new/unknown, even when there are no guarantees what the outcome will be" and trust in yourself and others that you will make the right judgement and take the right course of action: "Trust your gut instinct/intuition".

Accommodation of conative weaknesses included an awareness and promotion of others' needs before one's own (e.g., selflessness and humility; "being able to understand other's needs and uphold them over your own") which concurrently thwarts one's ability to recognise and fulfil one's own needs. Tolerance of unfulfilled needs was also recognised by participants who endorsed patience as an attribute of mental toughness (e.g., "if you can wait and not be tired by waiting"). Participants mentioned empathy and compassion as an attribute of mental toughness (e.g., "concern for the welfare of others"), which ultimately ties one's emotions, attitudes and thoughts to the suffering of others and subsequently restricts self-preservation, free choice and control. Finally, a tolerance of uncontrollable external environments was reflected in responses that included acceptance (e.g., "knowing you can't control everything", "being able to acknowledge that and realising sometimes that is just how the 'cards get dealt'...."), faith in external variables or higher powers (e.g., "if you find yourself in a bad situation you can have faith that your luck/situation will change in time", "I always believe that whatever can't be done anymore, it is up to God. He will do the rest"), flexibility in decisions and plans ("happy to change decisions as things change") and self-compassion ("do the best you can, and know that no one can ask more of you than that").

Finally, accommodation of affective weaknesses included an ability to tolerate negative affect. In particular, a number of participants commented on attributes of emotional detachment (e.g., "the ability to compartmentalise negative emotion") and independence from negative emotions (e.g., "accepting your emotions and not being controlled by them").

\subsection{Theme 3: Outputs}

Within this theme, a number of outcomes and behaviours were noted by participants which generally fell into the categories of surviving, striving and thriving.

\subsubsection{Striving}

In terms of surviving, participants typically used words such as "surviving", "get through", "handle" or "overcoming". Resilience was commonly mentioned by participants, which was referred to recovery from both internal strain and external stress: "the ability to quickly recover from mental fatigue, poor motivation and self-pity" and "bouncing back from setbacks as a result of determination to succeed."Within the theme of surviving, some participants specifically mentioned an ability to maintain both personal (e.g., self-preservation) and social (e.g., relationship preservation) wellbeing; for example, "to be able to deal with these situations with the least amount of 
personal damage inflicted, i.e., damage to relationships, stress and health, damage to personal confidence and self-esteem, and minimum of anxiety". In service of maintaining wellbeing, participants mentioned the ability of mentally tough individuals to talk about feelings with others, take time out for self-care activities, and desist in an uncontrollable situation or acquiesce to avoid conflict if that was what the situation required.

Mental toughness was also associated with the maintenance of virtuous behaviour despite internal or external pressure to act otherwise. In particular, virtuous behaviours included an ability to "remain true to yourself and your beliefs" (i.e., authenticity, assertiveness), "being able to accept responsibility for your own stuff if it goes wrong" (i.e., honesty, integrity, responsibility/accountability), "never allowing oneself to complain or to criticise" (i.e., stoicism) and altruism, generosity and kindness towards others (e.g., "being able to sacrifice things for the greater good").

Further to wellbeing and virtues, preservation of one's capacity to function under stress (e.g., consistency, performance under pressure, perform to potential) was identified by a number of participants: "to be able to continue functioning constructively in spite of challenging circumstances". As an illustration, one participant commented on how mental toughness enabled a friend to navigate complex and threatening situations whilst still maintaining necessary day-to-day activities e.g., [mental toughness has] "helped her keep her children safe, keep working, negotiate complex criminal legal proceedings". Maintenance of functioning was also reflected in behaviours that demonstrated personal effectiveness, such as having or showing good judgement, decisiveness, effective communication and leadership.

\subsubsection{Striving}

On the other hand, striving was oriented towards the maintenance of goals and visions under stress, described by one participant as: "effectively maintaining my own mental toughness in order to keep the "mission" or dream alive". In particular, goal maintenance included rigid behaviours that continued in spite of discomfort or fatigue (e.g., persistence, perseverance, endurance and hard work; "persistence-keep going until the job gets done") and negative emotions (e.g., courage; "feel the fear and do it anyway").

\subsubsection{Thriving}

The final outcome of thriving went beyond surviving (e.g." "it is being taken out of your comfort zone, and surviving, and even succeeding") to include success, achievement, growth (such as learning and skill development: "improving from failure") and "innovation".

\section{Discussion}

Current conceptualisations of mental toughness provide limited differentiation between causes, processes and outputs (Hardy et al., 2014). Thus, despite their contribution for describing mental toughness (Middleton et al., 2004; Sorensen et al., 2016) and informing measurement (e.g., Clough et al., 2002), existing theories have so far provided 
a limited understanding of the "engine" of mental toughness. The current study addresses this shortcoming by identifying the inputs, processes and outputs of mental toughness.

First, inputs included personal resources (personality, experience, social support, morals, values and religion) and stressors (external stress and internal strain). When considered together, personal resources and external stressors may represent the degree of person-environment fit, which subsequently determined the amount of internal strain that was experienced by an individual (French, Caplan, \& Harrison, 1982). This element of mental toughness is referred to by Gucciardi et al. (2015), who position mental toughness as a "resource caravan" in the interaction between resources and demands. As such, inputs of personal resources and stressors may influence mental toughness by determining the strategy that is employed (i.e., strength or accommodation) and the extent to which outputs of mental toughness are subsequently achieved (i.e., surviving, striving and/or thriving).

Regarding the specific content of these inputs, the personal resources mentioned by participants converge with both inherent versus developed perspectives of mental toughness, which suggest genetic and relatively fixed personality traits on one hand (e.g., Clough et al., 2010; Horsburgh, Schermer, Veselka, \& Vernon, 2009) and developmental or environmental inputs on the other hand (such as experience and role models; Collins \& MacNamara, 2012; Connaughton, Wadey, Hanton, \& Jones, 2008; Mahoney, Gucciardi, Mallett, \& Ntoumantis, 2014). Although this distinction exists, the present findings support many conceptualisations of mental toughness that recognise dual-input from both internal and external inputs (Bull et al., 2005; Coulter et al., 2010; Gucciardi et al., 2009a; Jones et al., 2002; Mahoney et al., 2014; Thelwell et al., 2005; see Crust, 2008 for a review). Particularly noteworthy is the finding that, to be effective inputs, social supports need to be admired but do not require direct verbal contact. This finding corroborates assertions by Mahoney et al. (2014) who suggest that conditions apply for input variables (such as social support) to be effective, which raises important avenues for future research and carries implications for the delivery of mental toughness interventions.

Less supported are the input variables of morals, values, religion and physiological wellbeing. Although Gucciardi et al. (2008) and Coulter et al. (2010) include personal values as an attribute of mental toughness (e.g., integrity and honesty), ethical and religious inputs are relatively absent in the mental toughness literature. Moreover, although a number of empirical investigations note the importance of physiological wellbeing for mental toughness, such as sufficient sleep and exercise (Brand et al., 2013; Gerber et al., 2012), this input has gone relatively unnoticed in the mental toughness development literature. Because ethics are more applicable to everyday life and elite athletes are presumably physiologically healthy already, we suggest that these new findings may result from the use of lay vis-à-vis expert sporting samples.

By using laypeople as participants in the current study, we also found an extensive range of stressors that differed somewhat from those specified in sporting-focused 
models by Gucciardi et al. (2008), Coulter et al. (2010) and Slack, Butt, Maynard and Olusoga (2014). Although Gucciardi et al. (2008) and Coulter et al. (2010) also distinguish between internal and external pressures and some overlap is evident within these (such as challenges, fatigue and confidence), the situations identified here extend beyond sports-specific situations to include a wider variety of life, social, vocational and achievement-oriented stressors. These findings thus support assertions of the applicability of mental toughness beyond sporting contexts (e.g., Gucciardi et al., 2015) and subsequently provide a richer understanding of the non-sporting applications of mental toughness (see Appendix).

Second, processes of mental toughness were identified as strength and accommodation. This dichotomy reflects an individual's capacity to perform and maintain cognitive, conative and affective functions under stress, as well as one's capacity to accommodate intrinsic weaknesses or barriers (i.e., internal strains) within cognitive, conative and affective faculties. The first interesting finding was the clear allocation of data into cognitions, conation and affection within each process. Allocation of data into these faculties aligns with those distinctions made by Ryba, Stambulova and Wrisberg (2009), who liken mental toughness to volition and distinguish between three constituents of intellectual (cognitive), affective (motivational) and operational components (skills, i.e., purposeful behaviours to overcome obstacles). Attributes of mental toughness identified in previous research also include cognitive (e.g., good decision-making, self and situational awareness, knowledge and understanding; Bull et al., 2005; Coulter et al., 2010; Gucciardi et al., 2008; Jones, Hanton, \& Connaughton, 2002; Thelwell et al., 2005; Weinberg et al., 2011), conative (e.g., self-belief, emotional control, preparation, focus and concentration; Bull et al., 2005; Coulter et al., 2010; Driska, Kamphoff, \& Armentrout, 2012; Gucciardi et al., 2008; Jones et al., 2002; Jones \& Moorhouse, 2007; Thelwell et al., 2005) and affective (e.g., calm, enjoyment of pressure; Driska et al., 2012; Jones et al., 2002; Thelwell et al., 2005) components of mental toughness. Accordingly, the faculties of cognition, conation and affection (also referred to as knowing, willing and feeling) represent constituents of "the mind" (Hilgard, 1980; Huitt \& Cain, 2005) and may thus represent the underlying psychological dimensions involved in mental toughness.

Regarding the specific processes of strength and accommodation, evidence to support this dichotomy is available throughout the mental toughness literature despite remaining previously unidentified. For example, Gucciardi et al. (2008) cite self-belief as a characteristic of mental toughness (i.e., strength), but also concurrently identifies mental toughness as relevant to situations of low or challenged self-belief (i.e., accommodation). Similarly, although current conceptualisations of mental toughness endorse characteristics akin to mental health (e.g., self-belief, motivation), Andersen (2011) argues that mental toughness also includes a capacity to function in spite of mental illness, such as clinical depression (i.e., accommodation of internal strain). Extending beyond the mental toughness literature, general psychological interventions, such as Cognitive Behavioural Therapy (CBT) and Acceptance Commitment Therapy (ACT) 
differ in their objectives to control (i.e., strength; CBT, Beck, 2011) or accept (i.e., accommodation; ACT, Hayes, Strosahl, \& Wilson, 2012) disturbing thoughts and emotions. As such, processes of strength and accommodation may underlie mental toughness and also extend to applications beyond this construct.

The identification of strength and accommodative processes may also compensate for the problem of "fantasies and absolute language" (Andersen, 2011: p. 73) evident throughout current conceptualisations of mental toughness. Specifically, Andersen (2011) suggests that absolute and rigid attributes such as "unshakeable belief" (Jones et al., 2002) are unrealistic and may instead contribute to maladaptive outcomes in the face of disconfirming information. For instance, mental toughness may contribute to poor rehabilitation and recovery outcomes due to individuals appraising their injuries as less severe or less likely to re-occur (Levy, Polman, Clough, Marchant, \& Earle, 2006). Rather than lending support to either argument, however, the current framework satisfies both perspectives by conceptualising mental toughness as a dichotomy between rigidity (i.e., strength) and accommodation of internal strains (i.e., accommodation).

Finally, the outputs of surviving, striving and thriving were identified from voluntary behaviours and outcomes associated with mental toughness. Although current findings highlighted the new output of maintaining positive virtues (see Appendix A), the outputs identified here corroborate those identified in previous literature (e.g., Gucciardi et al., 2015). However, despite support for a wide range of outcomes from current and previous findings, the mental toughness literature remains predominantly oriented towards performance or achievement outcomes. For example, recent definitions of mental toughness include:

" $A$ collection of personal characteristics (i.e., forces, resources, and demands, discussed later) that allow individuals to regularly perform to or around the best of their abilities regardless of circumstances faced” (Mahoney et al., 2014: p. 234), and

"A personal capacity to produce consistently high levels of subjective (e.g., personal goal achievement) and objective (e.g., race times) performance despite everyday challenges and stressors as well as significant adversities" (Gucciardi et al., 2015: p. 28).

On this basis, conceptualisations of mental toughness "lag" recent qualitative and empirical knowledge linking mental toughness to outcomes beyond performance and achievement (including maintenance of wellbeing; Gerber, Brand et al., 2013; Gerber, Kalak et al., 2013; Gucciardi et al., 2015).

\subsection{Aggregation of Findings into a Systems-Approach Model of Mental Toughness}

As a step toward remedying this conceptual "lag" and piecemeal understanding of mental toughness, based on the findings of the current study, we present the aggregated systems-approach model of mental toughness in Figure 1.

When viewed in its entirety, this model provides a "bird's eye view" of mental toughness, which includes the full range of inputs, processes and outputs. Attributes of 


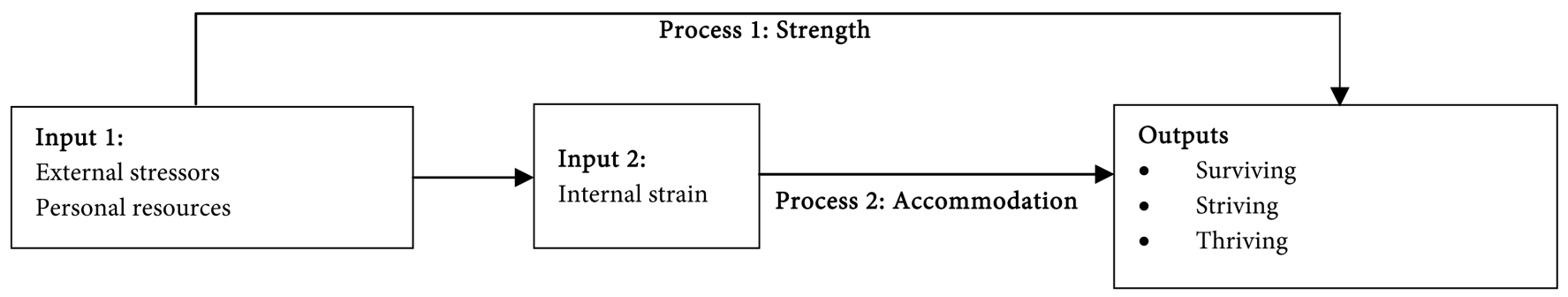

Figure 1. A systems-approach model of mental toughness derived from thematic analysis of raw data.

mental toughness are housed within these components (see Appendix), which lends coherence to the chaotic, plentiful and sometimes contradictory list of attributes already available in the mental toughness literature (Andersen, 2011). As this model is an extension of existing models, it also carries a number of new implications for mental toughness theory, measurement and development. What follows is a theoretical discussion of this model and its implications.

Figure 1 illustrates the causal pathway from inputs to outputs either through strength or accommodative processes. In particular, Figure 1 illustrates strength as the capacity to perform and maintain psychological functions under stress (see Appendix); that is, cognitive, conative and affective faculties are not influenced by external stress. Alternatively, in the case of internal strain within cognitive, conative and/or affective faculties, accommodative processes (see Appendix) assist in sustaining one or more outputs of surviving, striving and thriving. Ultimately, we theorise that a balance between these two pathways is most facilitative of mental toughness, whereby an imbalance may result in "brittleness" (i.e., high external stress tolerance but low internal strain tolerance) or "susceptibility" (i.e., low external stress tolerance but high internal strain tolerance).

Overall, regardless of the pathway, mental toughness is a capacity to maintain one or more outputs (surviving, thriving and striving) under external stress and/or internal strain. As such, we define mental toughness as a resistance to psychological disintegration under stress ${ }^{1}$. In line with qualitative data, this definition includes resistance to disintegration in cognitive ability, will (or volition) and/or affect, depending on situational demands. This conceptualisation represents a move away from the restricted focus of performance and achievement, and extends the applicability of mental toughness to the wide range of contexts and outcomes identified here and throughout previous literature.

An important implication of this definition is that mental toughness may not simply be the sum of strength and accommodation. Instead, mental toughness may be the

\footnotetext{
${ }^{1}$ Psychological disintegration is a term used in suffering research to describe a condition of being overwhelmed by negative psychological states, such as negative emotions and beliefs (i.e., internal strain; Diekstra, 1981, as cited in Kuitert, 1995; Morse, 2001). This state typically interferes with functioning (Morse, 2001) and individuals are unable to regain this inner stability on their own (Diekstra, 1981 as cited in Kuitert, 1995). Thus, whether these negative psychological states (i.e., internal strain) are bypassed by strength processes or tolerated by accommodative processes to maintain one or more mentally tough outcomes, we suggest that $r e$ sistance to psychological disintegration sufficiently captures the essence of mental toughness.
} 
timely use of pathways (i.e., strength or accommodation) according to inputs (i.e., situational requirements and personal resources, or person-environment fit) in order to attain one or more outputs of surviving, striving and/or thriving. This proposition is supported by our data (e.g., "knowing when, and when not [emphasis added] to use your energy to persevere with something", "if appropriate [emphasis added], choose not to respond/react") as well as in previous literature. For example, Crust (2008) notes that athletes inappropriately persisting (i.e., strength) in the face of injury may risk long-term damage and compromise team efficiency; alternatively, the author suggests that mental toughness may instead be the ability to make the difficult decision to stop training and competing in order to recover from injury. In other words, knowing how to use each pathway, as well as also accurately identifying when to use them may be the key to mental toughness.

Considering this complex balance, the majority of existing measures of mental toughness that solely measure the presence or absence of chosen attributes and outcomes may provide a rather elementary and haphazard assessment of mental toughness. Similarly, interventions that aim to develop mental toughness through building one or more attributes of mental toughness (e.g., coping, optimism and various psychological skills; Bell, Hardy, \& Beattie, 2013; Gucciardi, Gordon, \& Dimmock, 2009b; Parkes \& Mallett, 2011; Sheard \& Golby, 2006) may also be limited in their ability to facilitate mentally tough behaviour and outcomes. These implications may extend to non-specific interventions that target strength or accommodative pathways (such as $\mathrm{CBT}$ and ACT) whereby these therapies may be more effective when the patient is taught how to use both strategies and when it is most appropriate to use each one. As such, measuring and developing the complex system of mental toughness remains a challenge for future research.

In sum, most of the attributes within inputs, processes and outputs of mental toughness have previously been proven to contribute towards mental toughness in their own right. However, our findings and subsequent systems-approach model of mental toughness suggest that discrimination between inputs, processes and outputs, as well as concurrent consideration of all these elements together, is necessary for completely and accurately understanding, measuring and developing mental toughness. On this basis, the systems-approach model of mental toughness presented here, which is grounded in qualitative data, may be the best foundation on which to base future research. We hope that both the framework and content of this systems-approach model of mental toughness continue to be investigated, consolidated and extended in order to formulate a robust theory of mental toughness, to ultimately foster surviving, striving and thriving in a wide range of contexts.

\subsection{Study Limitations}

Limitations of our research include subjective coding of qualitative data, the use of a questionnaire vis-à-vis in-depth interviews and feedback effects. First, as with any form of qualitative analysis, coding relied on a subjective interpretation of meanings inherent 
in the data. Although we aimed to mitigate this limitation by following the well-defined and detailed guide to thematic analysis by Braun and Clarke (2006), we acknowledge that biases and differences in conceptual understanding may always exist. Second, contrary to previous qualitative accounts of mental toughness (e.g., Coulter et al., 2010; Gucciardi et al., 2008; Jones et al., 2002; Thelwell et al., 2005), the present method used a written questionnaire to attain attributes of mental toughness. Although this approach was useful for obtaining a range of different opinions across a large sample size, the use of written questionnaires vis-à-vis in-depth interviews prevented us from elaborating meaning in some responses and gaining a clear idea of causal pathway. In line with causality, as recommended by Jayawickreme et al. (2012), it is possible that feedback effects may be present in the systems-approach model to mental toughness. In other words, direction of causality may instead be reversed from outputs to processes to inputs (although it is likely that this is not a main effect; Jayawickreme et al., 2012). Thus, aligned with these recommendations, the systems-approach model of mental toughness is intended as a "causal but not exhaustive one" (Jayawickreme et al., 2012: p. 336) whereby it remains open to important feedback effects that may be present.

\section{References}

Andersen, M. B. (2011). Who's Mental, Who's Tough and Who's Both? In D. Gucciardi, \& S. Gordon (Eds.), Mental Toughness in Sport: Developments in Theory and Research (pp. 69-88). London: Taylor \& Francis.

Beck, J. S. (2011). Cognitive Behaviour Therapy: Basics and Beyond (2nd ed.). New York: Guilford Press.

Bell, J. J., Hardy, L., \& Beattie, S. (2013). Enhancing Mental Toughness and Performance under Pressure in Elite Young Cricketers: A 2-Year Longitudinal Intervention. Sport, Exercise, and Performance Psychology, 2, 281-297. http://dx.doi.org/10.1037/a0033129

Brand, S., Gerber, M., Kalak, N., Kirov, R., Lemola, S., Clough, P. J. et al. (2013). Adolescents with Greater Mental Toughness Show Higher Sleep Efficiency, More Deep Sleep and Fewer Awakenings after Sleep Onset. Journal of Adolescent Health, 54, 109-113.

http://dx.doi.org/10.1016/j.jadohealth.2013.07.017

Braun, V., \& Clarke, V. (2006). Using Thematic Analysis in Psychology. Qualitative Research in Psychology, 3, 77-101. http://dx.doi.org/10.1191/1478088706qp063oa

Bull, S. J., Shambrook, C. J., James, W., \& Brooks, J. E. (2005). Towards an Understanding of Mental Toughness in Elite English Cricketers. Journal of Applied Sport Psychology, 17, 209227. http://dx.doi.org/10.1080/10413200591010085

Clough, P. J., Earle, K., \& Sewell, D. (2002) Mental Toughness: The Concept and Its Measurement. In I. Cockerill (Ed.), Solutions in Sport Psychology (pp. 32-43). London: Thomson.

Clough, P., \& Strycharczyk, D. (2012). Developing Mental Toughness: Improving Performance, Wellbeing and Positive Behavior in Others. London: Kogan Page.

Clough, P., Newton, S., Bruen, P., Earle, K., Earle, F., Benuzzi, F. et al. (2010). Mental Toughness and Brain Structure. Poster presented at the 16th Annual Meeting of the Organisation for Human Bran Mapping, Barcelona, Spain, June 2010.

Collins, D., \& MacNamara, À. (2012). The Rocky Road to the Top. Sports Medicine, 42, 907-914. http://dx.doi.org/10.1007/BF03262302 
Connaughton, D., Wadey, R., Hanton, S., \& Jones, G. (2008). The Development and Maintenance of Mental Toughness: Perceptions of Elite Performers. Journal of Sports Sciences, 26, 83-95. http://dx.doi.org/10.1080/02640410701310958

Coulter, T., Mallett, C. J., \& Gucciardi, D. F. (2010). Understanding Mental Toughness in Australian Soccer: Perceptions of Players, Parents, and Coaches. Journal of Sports Sciences, 28, 699716. http://dx.doi.org/10.1080/02640411003734085

Crust, L. (2008). A Review and Conceptual Re-Examination of Mental Toughness: Implications for Future Researchers. Personality and Individual Differences, 45, 576-583. http://dx.doi.org/10.1016/j.paid.2008.07.005

Diekstra, R. F. W. (1981). Over Sucide. Alphen aan den Rijn: Samsom.

Driska, A. P., Kamphoff, C., \& Armentrout, S. M. (2012). Elite Swimming Coaches' Perceptions of Mental Toughness. The Sport Psychologist, 26, 186-206.

http://dx.doi.org/10.1123/tsp.26.2.186

Fehr, L., \& Russell, J. A. (1984). Concept of Emotion Viewed from a Prototype Perspective. Journal of Experimental Psychology: General, 113, 464-486. http://dx.doi.org/10.1037/0096-3445.113.3.464

French, J. R. P., Caplan, R. D., \& Harrison, R. V. (1982). Mechanisms of Job Stress and Strain. New York: John Wiley.

Gerber, M., Brand, S., Feldmeth, A. K., Lang, C., Elliot, C., Holsboer-Trachsler, E., \& Pühse, U. (2013). Adolescents with High Mental Toughness Adapt Better to Perceived Stress: A Longitudinal Study with Swiss Vocational Students. Personality and Individual Differences, 54, 808814. http://dx.doi.org/10.1016/j.paid.2012.12.003

Gerber, M., Kalak, N., Lemola, S., Clough, P. J., Pühse, U., Elliot, C. et al. (2012). Adolescents' Exercise and Physical Activity Are Associated with Mental Toughness. Mental Health and Physical Activity, 5, 35-42. http://dx.doi.org/10.1016/j.mhpa.2012.02.004

Gerber, M., Kalak, N., Lemola, S., Clough, P., Perry, J. L., Pühse, U. et al. (2013). Are Adolescents with Higher Mental Toughness More Resilient Against Stress? Stress and Health, 29, 164-171. http://dx.doi.org/10.1002/smi.2447

Gucciardi, D. F., Gordon, S., \& Dimmock, J. A. (2008). Towards an Understanding of Mental Toughness in Australian Football. Journal of Applied Sport Psychology, 20, 261-281. http://dx.doi.org/10.1080/10413200801998556

Gucciardi, D. F., Gordon, S., \& Dimmock, J. A. (2009a). Advancing Mental Toughness Research and Theory Using Personal Construct Psychology. International Review of Sport and Exercise Psychology, 2, 54-72. http://dx.doi.org/10.1080/17509840802705938

Gucciardi, D. F., Gordon, S., \& Dimmock, J. A. (2009b). Evaluation of a Mental Toughness Training Program forYouth-Aged Australian Footballers: I. A Quantitative Analysis. Journal of Applied Sport Psychology, 21, 307-323. http://dx.doi.org/10.1080/10413200903026066

Gucciardi, D. F., Hanton, S., Gordon, S., Mallett, C. J., \& Temby, P. (2015). The Concept of Mental Toughness: Tests of Dimensionality, Nomological NetworkandTraitness. Journal of Personality, 83, 26-44. http://dx.doi.org/10.1111/jopy.12079

Hagerty, M. R., Cummins, R. A., Ferriss, A. L., Land, K., Michalos, A. C., Peterson, M. et al. (2001). Quality of Life Indexes for National Policy: Review and Agenda for Research. Social Indicators Research, 55, 1-96. http://dx.doi.org/10.1023/A:1010811312332

Hardy, L., Bell, J., \& Beattie, S. (2014). A Neuropsychological Model of Mentally Tough Behavior. Journal of Personality, 82, 69-81. http://dx.doi.org/10.1111/jopy.12034

Hayes, S. C., Strosahl, K. D., \& Wilson, K. G. (2012). Acceptance and Commitment Therapy: The 
Process and Practice of Mindful Change (2nd ed.). New York: Guilford Press.

Hilgard, E. R. (1980). The Trilogy of Mind: Cognition, Affection and Conation. Journal of the History of the Behavioral Sciences, 16, 107-117. http://dx.doi.org/10.1002/1520-6696(198004)16:2<107::AID-JHBS2300160202>3.0.CO;2-Y

Horsburgh, V. A., Schermer, J. A., Veselka, L., \& Vernon, P. A. (2009). A Behavioural Genetic Study of Mental Toughness and Personality. Personality and Individual Differences, 46, 100105. http://dx.doi.org/10.1016/j.paid.2008.09.009

Huitt, W., \& Cain, S. (2005). An Overview of the Conative Domain. In Educational Psychology Interactive (pp. 1-20). Valdosta, GA: Valdosta State University.

Jayawickreme, E., Forgeard, M. J., \& Seligman, M. E. (2012). The Engine of Well-Being. Review of General Psychology, 16, 327-342. http://dx.doi.org/10.1037/a0027990

Jones, G., \& Moorhouse, A. (2007). Developing Mental Toughness: Gold Medal Strategies for Transforming your Business Performance. Oxford, UK: Spring.

Jones, G., Hanton, S., \& Connaughton, D. (2002). What Is This Thing Called Mental Toughness? An Investigation of Elite Sport Performers. Journal of Applied Sport Psychology, 14, 205-218. http://dx.doi.org/10.1080/10413200290103509

Kuitert, H. M. (1995). Ethical and Legal Problems in Connection with Suicide Prevention. In R. F. Diekstra, W. Gulbinat, I. Kienhorst, \& D. de Leo (Eds.), Preventive Strategies on Suicide (pp. 273-291). New York: EJ Brill.

Levy, A. R., Polman, R. C., Clough, P. J., Marchant, D. C., \& Earle, K. (2006). Mental Toughness as a Determinant of Beliefs, Pain, and Adherence in Sport Injury Rehabilitation. Journal of Sport Rehabilitation, 15, 246-254. http://dx.doi.org/10.1123/jsr.15.3.245

Mahoney, J. W., Gucciardi, D. F., Mallett, C. J., \& Ntoumanis, N. (2014). Adolescent Performers' Perspectives on Mental Toughness and Its Development: The Utility of the Bioecological Model. The Sport Psychologist, 28, 233-244.

http://dx.doi.org/10.1123/tsp.2013-0050

Middleton, S. C., Marsh, H. W., Martin, A. J., Richards, G. E., \& Perry, C. (2004) Discovering Mental Toughness: A Qualitative Study of Mental Toughness in Elite Athletes. Australia: SELF Research Centre, University of Western Sydney.

http://www.sectiononewrestling.com/discovering_mental_toughness.pdf

Morse, J. M. (2001). Towards a Praxis Theory of Suffering. Advances in Nursing Science, 24, 47-59. http://dx.doi.org/10.1097/00012272-200109000-00007

Parkes, J. F., \& Mallett, C. J. (2011). Developing Mental Toughness: Attributional Style Retraining in Rugby. The Sport Psychologist, 25, 269-287. http://dx.doi.org/10.1123/tsp.25.3.269

Ryba, T. V., Stambulova, N. B., \& Wrisberg, C. A. (2009). Forward to the Past: Puni's Model of Volitional Preparation in Sport. International Journal of Sport and Exercise Psychology, 7, 275-291. http://dx.doi.org/10.1080/1612197X.2009.9671910

Sheard, M., \& Golby, J. (2006). Effect of a Psychological Skills Training Program on Swimming Performance and Positive Psychological Development. International Journal of Sport and EXercise Psychology, 4, 149-169. http://dx.doi.org/10.1080/1612197X.2006.9671790

Slack, L. A., Butt, J., Maynard, I. W., \& Olusoga. P. (2014). Understanding Mental Toughness in Elite Football Officiating: Perceptions of English Premier League Referees. Sport and Exercise Psychology Review, 10, 4-24.

Sorensen, S. H., Jarden, A., \& Schofield, G. (2016). Lay Perceptions of Mental Toughness: Understanding Conceptual Similarities and Differences between Lay and Sporting Contexts. International Journal of Wellbeing, 6, 71-95. 
Thelwell, R., Weston, N., \& Greenlees, I. (2005). Defining and Understanding Mental Toughness within Soccer. Journal of Applied Sport Psychology, 17, 326-332.

http://dx.doi.org/10.1080/10413200500313636

Weinberg, R., Butt, J., \& Culp, B. (2011). Coaches' Views of Mental Toughness and How It Is Built. International Journal of Sport and Exercise Psychology, 9, 156-172.

http://dx.doi.org/10.1080/1612197X.2011.567106 


\section{Appendix: Full List of Themes Obtained from the Raw Data}

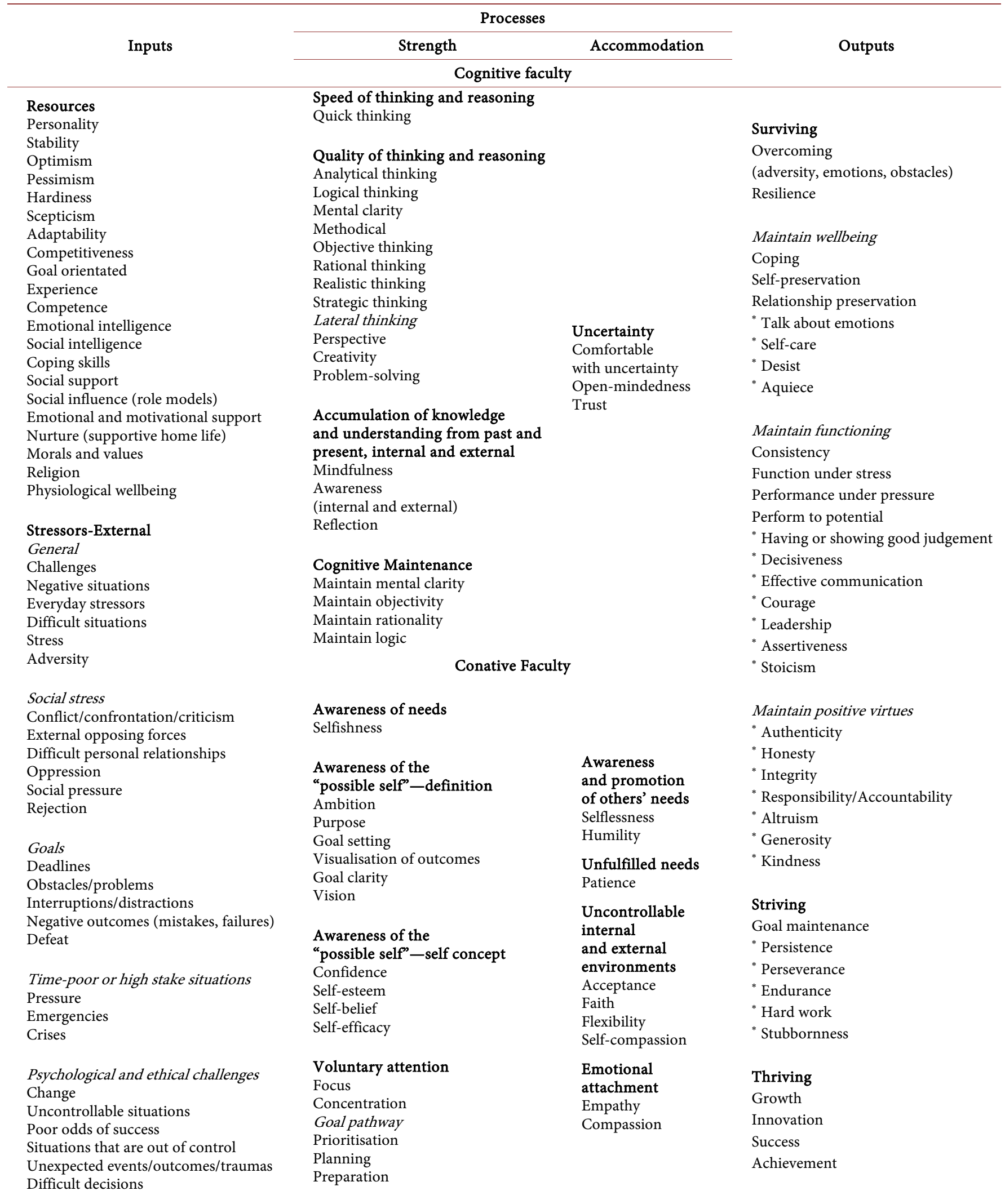




\section{Continued}

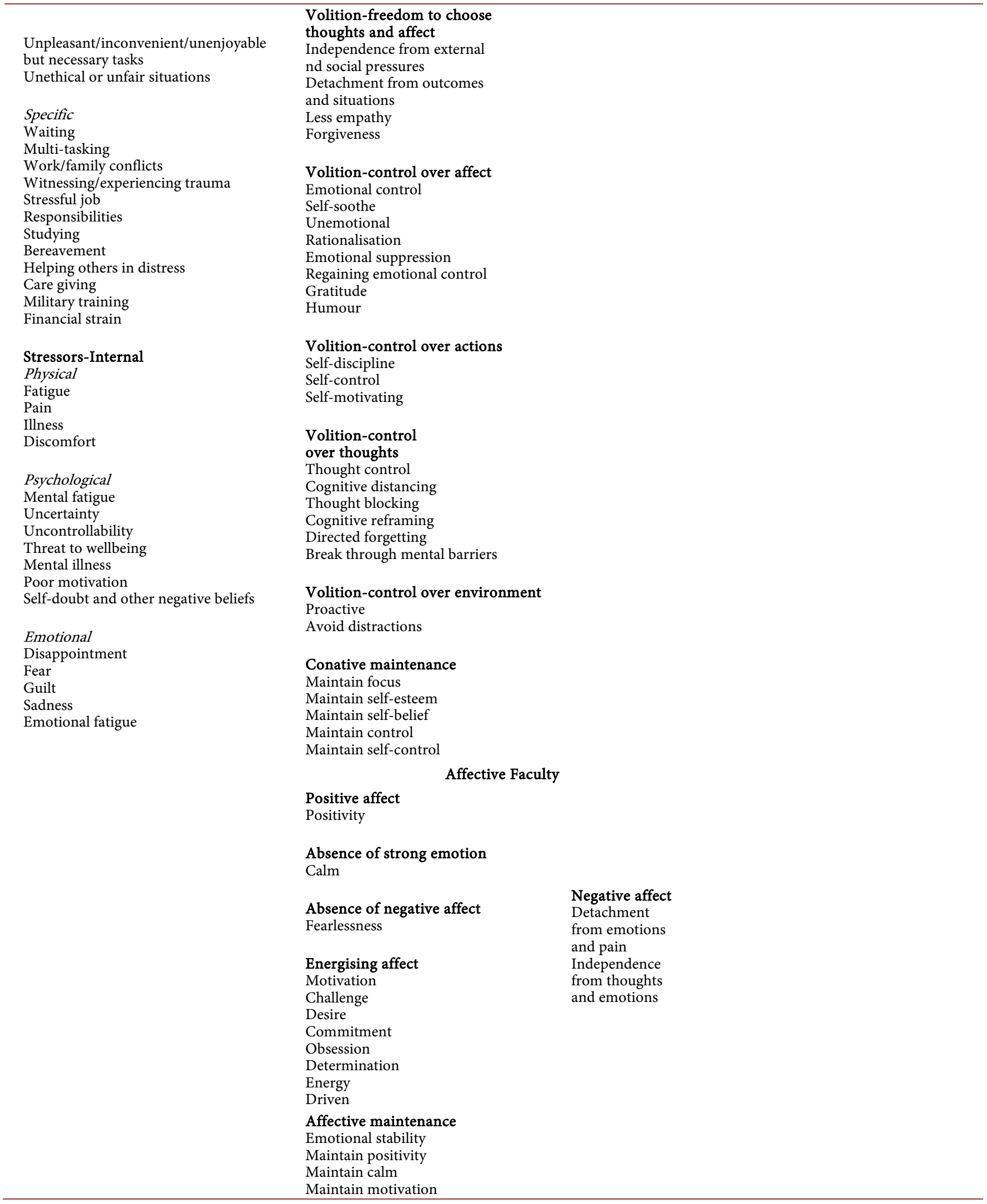

